\title{
Research on the Internationalization of Yunnan Cultural Industry in the Context of "Belt and Road Initiative"
}

\author{
Wenhua Yang* \\ International Business School \\ Yunnan University of Finance and Economics \\ Kunming, China \\ 362941296@qq.com
}

\author{
Chunyang $\mathrm{Li}$ \\ School of Economics \\ Yunnan University of Finance and Economics \\ Kunming, China \\ 767061319@qq.com
}

\begin{abstract}
The proposal of "Belt and Road Initiative" has brought opportunities for the political, economic and cultural development in Yunnan, which is conducive to exchanges and trade between various ethnic groups in Yunnan and neighboring countries and regions. One of the important missions of the Belt and Road Initiative is to improve the "Belt and Road" cultural exchange and cooperation platform, create "Belt and Road" cultural exchange brands, and promote the prosperity of the "Belt and Road" cultural industry. In this context, the scale of Yunnan's ethnic cultural industry has continued to expand and has achieved some remarkable results. However, despite the rapid development of Yunnan ethnic cultural industry, its international competitiveness is not very strong. This paper analyzes the current development of the cultural industry in Yunnan and the major problems it faces. Then this paper proposes that Yunnan's cultural industry should integrate diverse resources of Yunnan ethnic nationalities characteristics with innovation and communication channels. Besides, Yunnan local governments should place emphasis on the cultivation of creative talents in addition to financial support to Yunnan cultural enterprises. Advanced technology and communication channels should be applied to high-quality cultural products and services so that the so called "cultural soft power" can be improved eventually.
\end{abstract}

Keywords: Belt \& Road Initiative (BRI), cultural industry, internationalization

\section{INTRODUCTION}

"Belt \& Road Initiative"(BRI) was first proposed in the fall of 2013 by Xi Jinping, the President of China, with aims to promote regional integration between China and other Asian, African, and European countries through cooperation in the areas of infrastructure construction, cultural exchange, economy and trade.

Remarkable accomplishments have achieved since then and Chinese government is now determined to further boost funding for BRI projects. In December of 2016, the Ministry of Culture of China issued "Belt \& Road Initiative" Cultural Development Action Plan (2016-2020). This action plan states that the missions of BRI are to improve the cultural exchange and cooperation mechanism of the "Belt and Road"; strengthen the "Belt and Road" cultural exchange and cooperation platform and build the "Belt and Road" cultural exchange brands; promote the prosperity and development of the "Belt and Road" cultural industry, and support the "Belt and Road" cultural and trade cooperation [1]

At the same time, in its 13th five-year plan, the Chinese government clearly proposes that cultural industry should be developed into the backbone industry of Chinese national economy by 2020 . It is also stated that the added value of cultural industry should account for more than $5 \%$ of the national GDP with the total revenue more than RMB 4 trillion. Therefore, cultural industry has a promising future in China.

The cultural industry is an industry that engages in the creation, production, and distribution of products and services with cultural attributes. In 2004, the National Bureau of Statistics of China defined the cultural industry as a collection of activities that provide culture, entertainment products and services to the public, and other activities associated with them. The cultural industry is divided into two categories based on this definition: cultural services (main cultural industries) and related cultural services (relevant cultural industries). Based on the departmental management requirements and the characteristics of cultural activities, the cultural industry can also be classified into the following categories: news services, publishing and copyright services, radio, television and movie services, literature and art services, online cultural services, cultural and recreational services, other cultural services, manufacturing and sales of cultural goods/equipment and related cultural products.

While the cultural industry has a promising future, its development is not smooth, and the internationalization of the cultural industry is even difficult since it involves a lot of factors, including the quality and the design of cultural products, and most importantly, the domestic and international market. The internationalization of the cultural industry determines the extent of its impact on a country's international strategy. As large as the Chinese cultural industry is, its international competitiveness in cultural services and high-end cultural products is far behind that of the USA or Japan, even behind that of South Korea. China's cultural products exported mainly are labor-intensive and low-ended or low value-added

*Corresponding author 
products. So far, there are no cultural products that can be as influential as those of Hollywood, Disney or Japanese cartoons. Chinese food is well known in the world with thousands years' history, unfortunately, no one kind of Chinese food can compete with McDonald's or KFC in the world. Many American's cultural products are so popular that people's ideas or values in other countries are more or less affected by American values. Therefore, developing its cultural industry is essential to promote the diffusion of culture or cultural value if one country wants to improve its international influence. And the core content of the cultural industry is to provide cultural products or services.

\section{LITERATURE REVIEW}

BRI has aroused wide concern in the academic communities since it was put forward in 2013. Almost all scholars in China agree that BRI will not only be a channel for trade and economic cooperation, but also a bridge of civilization exchanges and cultural communication between China and other BRI countries and regions.

Yu (2017)[2] and An (2018)[3] study Chinese cultural industry under the background of BRI from a broad perspective, treating cultural industry in China as a whole unit. Their study suggest that the development of cultural industry in China requires the integration of traditional culture resources, especially ethnic cultural resources, with modern technology. Besides local governments' policy support and market deregulation, the current cultural industry system needs to be upgraded to cultivate market-oriented cultural products.

Sun and $\mathrm{Yu}$ (2016) believe that cultural distance is one important factor when Chinese enterprises conduct foreign direct investment in BRI countries and regions. They believe resource-seeking enterprises should choose countries with similar cultures to China while market-seeking enterprises should choose countries with different cultures, However, cultural distance makes no big differences for those strategic assets[4].

Some scholars focus their study on cultural industry in Yunnan. They put some suggestions after analyzing the good practices of the ethnic cultural industry in Yunnan as well as the main difficulties and barriers.(Yang and $\mathrm{Na}, 2015$, Gong and Xing, 2012)[5,6]. Li, Zhao and Shen (2016) believe that cultural industry in Yunnan tends to rely too much on the entertainment market. What's worse, cultural creativity or cultural innovation is scarce and software designing capability is weak. This factor, together with the fact that small size and short of funds, contributes to the decline in the added value of cultural industries in Yunnan in recent years[7]

The review of the literature shows that while some researches have touched the issue of cultural industry in the BRI context, they failed to discuss Yunnan's specific situation. The researches which focus on Yunnan cultural industry failed to connect the cultural industry in Yunnan within the
BRI context. Therefore, this paper will focus on how Yunnan's cultural industry can be better adjusted in terms of internationalization to meet the requirement of BRI based on some second-hand statistics.

\section{CURRENT SITUATION OF YUNNAN'S CULTURAL INDUSTRY}

The internationalization of Yunnan's cultural industry will be conducive to the economic and cultural exchanges between Yunnan and other neighbouring countries and regions.

Yunnan has a unique advantage of developing a cultural industry. There are 26 ethnic groups in Yunnan. The minority ethnic groups' population accounts for one third of Yunnan province's total population. Diverse ethnic cultures have become the source of cultural industry development, providing broad prospects and unlimited business opportunities for the development of Yunnan ethnic cultural industry.

According to internationally recognized standards, the cultural industry will not become the backbone industry of the national economy until it accounts for more than 5\% of GDP. In 2015, cultural industry in China only accounted for $3.9 \%$ of GDP (it is even lower in most ethnic areas), while it was $31 \%$ in the United States, and 20\% in Japan( Li \& Zhang, 2016).[8] Statistics of the Ministry of Commerce of China showed that the import of cultural services in 2017 was US $\$ 23.22$ billion, while the export of cultural cultural services was only US $\$ 6.17$ billion. The import of cultural services increased by $20 \%$ compared with 2016 while the export of cultural services decreased by $3.9 \%$. The trade deficit amounted to US $\$ 17.5$ billion. Statistics of the Ministry of Commerce of China also showed that cultural products imported from BRI countries in 2017 was US $\$ 17.62$ billion, an increase of $18.5 \%$, which was $18.1 \%$ out of the total cultural products imported in China. This indicates that there is a prospect market in the area of cultural industry between China and BRI countries (Wang, 2017).[9]

In 2014, China's provincial and municipal cultural industry development index was developed based on the productivity, influence and driving force of cultural industries in various provinces and cities. Unfortunately, Yunnan was not included in the top ten(Ye, 2015).[10]

In recent years, the cultural industry in Yunnan has developed rapidly. Zhao, Yu and Hong (2018) indicated that the added value of cultural industry has increased from RMB 29.897 billion yuan in 2012 to RMB 45.365 billion yuan in 2016, including RMB 10.819 billion yuan in cultural manufacturing and RMB12.361 billion yuan in cultural wholesale and retail business, RMB 22.11 billion yuan in cultural services industry, and totally accounting for $24 \%$, $27.2 \%$ and $48.7 \%$ of the added value of the cultural industry, respectively. The proportion of cultural industry in GDP has increased from $2.9 \%$ in 2012 to $3.1 \%$ in 2016. The added value of Yunnan cultural industry ranked the 19th in China in 
2016, the 4th place in the west part of China. Its proportion in GDP ranked the 17th in the China and the 5th in the west of China [11].

Some cultural products with local Yunnan characteristics have been recognized in BRI countries because Yunnan has geographic advantage of proximity to Southeast Asia. For example, Dynamic Yunnan (also named Yunnan Impression Show), displays a magnificent original song and dance performance which has been performed in nearly 4,000 shows in more than 50 cities both at home and abroad since 2003. This show was directed by the famous artist Yang Liping in which different types of dances are performed to show the features of various minority tribes in Yunnan. Another show named the "Smile of Angkor", a tourism performance show, funded by Yunnan Cultural Investment Group, has stationed in Cambodia for a long time. Kunming Xinzhi Group has built 9 overseas Chinese bookstores in Phnom Penh, Cambodia, Vientiane, Laos, and Kuala Lumpur, Malaysia, with a total of more than 160,000 square meters and more than 2,200 employees (Zhao et al, 2018)[12].

However, compared with some more developed provinces such as Guangdong and Zhejiang, the added value of Yunnan's cultural industry is relatively low. The development of Yunnan cultural industry is hindered basically because of less-developed economy in Yunnan Province, imbalance of cultural industry development and the scarce of innovation. On the other hand, the performing arts industry market which is well known in China only accounts for $2 \%$ of the total, and it is an area that is being neglected to certain extent. In addition, there are some other disadvantages such as the small scale of culture-related businesses in Yunnan, cultural resources are scattered. Therefore, it is very important to adjust the cultural industry market structure, and find new growth opportunities for the development of Yunnan's cultural industry. Yunnan lacks the industrial development ideas that attract international attention.though it is located in the "bridgehead" facing Southeast Asia. Yunnan's geographic advantage has not become the driving force to promote the development of Yunnan's cultural industry.

The ethnic minority economy in Yunnan is different from the core economic market in China. As a result, Yunnan's ethnic economy benefits less from the nation's economic growth to some extent. The economic development of Yunnan, which is dominated by rural economies, is relatively falling behind. Although there are abundant mineral resources, tourism and ethnic cultural resources, the development and innovation of ethnic cultural resources in Yunnan are still at an early stage. The abundant diverse ethnic cultural resources not only make Yunnan a typical "display platform" of China's ethnic cultural soft power in border areas, but also a favorable condition for its future development.

\section{OPPORTUNITIES AND CHALLENGES OF YUNNAN'S CULTURAL INDUSTRY IN THE CONTEXT OF BRI}

China is the leading country of BRI and Yunnan is located in the strategic position among BRI projects because its geographical location in China. Yunnan borders with Southeast Asian countries, including Myanmar, Vietnam and Laos. In the context of BRI, the cultural industry development in Yunnan is meeting great opportunities and some new challenges as well.

\section{A) BRI brings opportunities to Yunnan's cultural industry}

Yunnan is geographically adjacent to "two oceans" (Indian Ocean and Pacific Ocean) and crosses "two belts and one road" (the Yangtze River Economic Belt, the Silk Road Economic Belt, and the Maritime Silk Road Economic Belt). In the context of BRI, Yunnan plays an important role in "sea and land transportation", "important strategic hub" and "important strategic fulcrum". With the construction of ChinaMyanmar economic corridor, and international channels in Southeast Asia and South Asia, the overall internationalization of Yunnan has been improved.

In August 2019, Yunnan Pilot Free Trade Zones (YPFTZ) was established in Yunnan province, including Kunming free trade zone, Honghe Free Trade Zone and Dehong Free Trade Zone, totally covering 119.86 square kilometers. YPFTA aims to build an open international channel connecting South Asia and Southeast Asia by supporting innovation and economic development. YPFTZ will definitely facilitate trade and promote cross-border e-Commerce development between Yunnan and southeast Asian countries.

Many countries and regions in southeast Asia share similar cultural traditions and customs with ethnic group people in Yunnan. For example, some cross-border ethnic groups such as Dai minority group have similar customs with people in Thailand. Similar cultures are conducive to the spread of Chinese culture and active bilateral and multilateral cooperation. Kunming, the provincial capital, should be developed into an influential regional cultural center for Southeast Asia and South Asia because of its geographical and location advantages.

\section{B) BRI brings challenges to Yunnan's cultural industry}

Although the cultural industry in Yunnan is developing rapidly, its international competitiveness is not strong. The typical problems of cultural enterprises in Yunnan are small size, scattered with low productivity. Besides, the development of ethnic cultural products is generally insufficient and cultural products are homogenized.

Yunnan's cultural industry is hindered by short of funds because Yunnan's economy is less developed and local governments at all levels have limited funds to support cultural enterprises. In this case, Yunnan government should issue some favorable policies to encourage investment in prospect cultural enterprises. 
In addition, the cultural infrastructure of South Asia and Southeast Asian countries around Yunnan is poor, and the economic development model, social system and cultural foundation are different, which hinders the construction of the cultural exchange mechanism between Yunnan and the neighbouring countries.

Yunnan's cultural industry lacks modern management systems. High-quality and mature cultural products haven't been developed. Targeted cultural export market and development strategies based on the specific characteristics have not been developed, and as a result it can not meet the needs of the market of BRI countries. Besides, there is still no sound protection systems for overseas investment and overseas capital. The above factors contribute to the reality that Yunnan's cultural industry falls behind the development of the international market.

The last but not the least is that Yunnan does not have enough talents and related facilities of the cultural industry. Currently, only a few universities in Yunnan offer courses related to South Asian and Southeast Asian culture. Various cultural departments and enterprises do not have long-term talent training programs.The aging of cultural talents makes the situation even worse. In his paper "Discussion on Current Development of Yunnan's Ethnic Cultural Industry", Ding (2007) takes the most typical ethnic crafts and ethnic song and dance music culture industry as an example. Ding concluded that "the inheritance of ethnic culture is lacking, and the lack of talents engaged in ethnic cultural industries leads to a serious loss of ethnic culture" [13]. In the meantime, due to limited funds, cultural activities, especially the public welfare cultural industry, have not been invested enough, which has affected the development of cultural industries. Wang's study also indicates that it is tough for many enterprises to make large-scale production due to financial difficulties. The shortage of funds is a major obstacle to the development of cultural industries in Yunnan (2007)[14].

\section{SUGGESTIONS FOR PROMOTING THE DEVELOPMENT OF YUNNAN'S CULTURAL INDUSTRY IN THE CONTEXT OF BRI}

The fundamental significance of the "Belt and Road" Initiative is to support the economic development of neighboring countries through the construction of the Silk Road Economic Belt and the Maritime Silk Road, and at the same time accelerate the economic integration between China and these countries and create a new driving force for longterm growth.

To promote the development of the cultural industry, it is essential to have a long-term planning of cultural development Yunnan local governments at all levels should develop a longterm plan for the cultural industry in Yunnan by integrating cultural resources with modern technology. Talents are essential to achieve the prosperity and development of the cultural industry. The cultivation of cultural talents needs to be strengthened and a talent incentive mechanism needs to be established. Yunnan government should have some favorable policies for cultural talents development, such as providing favorable payment and better working conditions for talents in the cultural industry.

Besides, governments and universities should provide some training courses including languages used in Southern Asian and Southeast Asia countries, and offer talent training programs for multinational management. These training programs will be more effective if governments and universities can have cooperation programs with bordering countries so that both sides can have better understanding of their needs.

The existing cooperation mechanisms, including the Greater Mekong Economic Cooperation (GMS) and the ChinaASEAN Free Trade Area (CAFTA) will facilitate the cultural industry development between Yunnan and ASEAN countries. China-South Asia Expo is also an important platform to conduct cultural exchange.

The construction of a modern cultural industry system must be supported by modern high technology. The development of unique cultural industries also needs to employ modern science and technology, including internet, animation and software industries and big data.

Another important key to improve the international competitiveness of Yunnan's cultural industry is innovation. Dynamic Yunnan is so successful because it spotlights the unique character of Yunnan. This show blends original and primitive traditional songs and dances with new modern dance perfectly, showing the different dances from the minorities in Yunnan Province. Modern technology has also been applied into its background to show beautiful scenery in Yunnan.

Besides modern technology, it is also necessary to build a business model that uses cutting edge technology to influence cultural trade, promote cultural consumer services, and provide innovative cultural products and services that conform to the trend of modern technology.

\section{CONCLUSIONS}

Cultural industry is considered by the international community as the most promising industry in the 21 st century. It is of great significance for promoting the transformation and upgrading of traditional industries and enhancing overall national power and regional competitiveness. And BRI provides unlimited opportunities for the internalization of Yunnan's cultural industry. Cultural enterprises should have clear idea of its strategic value of the cultural industry in the the context of BRI. Governments in Yunnan should give priority support to the development of high value-added ethnic cultural industries in Yunnan, especially talents development. At the same time, cultural enterprises in Yunnan should have sensitive sense of market needs. They should continuously improve the creativity of cultural industries and develop 
innovative high-end cultural products to meet the the needs of consumers.

Cultures should be exchanged. The customs and cultural practices of the ethnic groups along the "Belt and Road" countries should be respected and followed during the interaction with them. BRI is about telling stories of China and stories of other countries as well. Otherwise, BRI would not be welcome by other countries.

\section{ACKNOWLEDGMENT}

Funding for this research was provided by Philosophy and Social Sciences Foundation of Yunnan Province of China under grant YB2019039.

\section{REFERENCES}

[1] http://www.gov.cn/gongbao/content/2017/content_5216447.htm

[2] Yu He. Research on the Internationalization of China's Cultural Industry under the Background of "Belt and Road" Strategy. Journal of Zhengzhou University (Social Sciences), Vol. 2, 2017, p80-85.

[3] Ning An, Research on the Diffusion and Promotion of Chinese National Culture in the Context of Belt and Road Initiative, No.1 Manchu Minority Research, 2018.1, p5-12

[4] Pengjun Sun, Peng Yu. The Impact of Cultural Distance on Chinese Enterprises' Strategy in the Context of Belt and Road Initiative, China Business and Market, 2016.2, p 83-90
[5] Wenhua Yang, Xia Na. On the Theories and Practice of Developing Ethnic Cultural Industry in Yunnan, Journal of Yunnan Socia Science,2015.01, p122-125

[6] Houqing Gong and Jingjing Xing. Literature Review of the Difficulties and Problems facing China's Ethnic Minority Cultural Industry,Journal of Sichuan University for Nationalities, Vol. 21, No. 4, 2012.08, p 50-55

[7] Xian Li, Yan Zhao, Meiyi Shen. Suggestions of Developing Cultural Industry in Yunnan, Finance \& Economy, 2018.08, p 32-34

[8] Hong Li, Jinyan Zhang. Reform and Transformation of Cultural Industries in Ethnic Areas [J]. Journal of Dalian Nationalities University, 2016.04

[9] Weijie Fang. Research on Development and Distribution of Foreign Cultural Trade of China under the perspective of "The Belt and Road", Journal of Prices, 2018.07

[10] Lang Ye. Annual Development Report of Chinese Cultural Industry [M]. Peking University Press, 2015

[11] Xiaohong Zhao, Youqi Yu, Liang Hong. Yunnan Cultural Industry Development Report, NEW WEST, 2018(7)

[12] Xiaohong Zhao, Youqi Yu, Liang Hong. Yunnan Cultural Industry Development Report, NEW WEST, 2018(7)

[13] Shuqun Ding. Discussion on Current Development of Ethnic Cultural Industry in Yunnan Province [J]. Journal of West Anhui University, Vol.1, 2007

[14] Peizhi Wang, etc. Yunnan Minority Cultural Industry Research [J]. Journal of Dali University, 2017(12) 